ECOLOGICA, Vol. 28, No 102 (2021), 264-270

https://doi.org/10.18485/ecologica.2021.28.102.18

Originalni naučni rad

UDC: $338.43 .02(497.11)$

\title{
Mere agrarne politike u funkciji održivog ruralnog razvoja Republike Srbije
}

\section{Agricultural policy measures in function of sustainable rural development of the Republic of Serbia}

\author{
Katarina Đurić ${ }^{1}$, Dragan Ivanišević ${ }^{2}$, Miralem Jahić ${ }^{3}$, Radivoj Prodanović ${ }^{4 \star}$ \\ ${ }^{1}$ Univerzitet u Novom Sadu, Poljoprivredni fakultet, Trg Dositeja Obradovića 8, Novi Sad, Srbija / \\ University of Novi Sad, Faculty of Agriculture, Trg Dositeja Obradovića 8, Novi Sad, Serbia \\ 2,3,4Univerzitet Privredna akademija, Fakultet za ekonomiju i inženjerski menadžment, Novi Sad, Srbija / \\ University of Business Academy, Faculty of Economics and Engineering Management, Novi Sad, Serbia \\ *Autor za prepisku / Corresponding author
}

Rad primljen / Received: 12.09.2020, Rad prihvaćen / Accepted: 18.05.2021.

\begin{abstract}
Sažetak: Cilj rada je utvrđivanje doprinosa mera agrarne politike ostvarivanju koncepta održivog ruralnog razvoja Republike Srbije. S obzirom da organska proizvodnja u najvećoj meri doprinosi ekološkoj održivosti ruralnih područja, u radu je analiziran uticaj subvencija na ekspanziju ove proizvodnje u našoj zemlji. Time je, na posredan način, analiziran uticaj mera agrarne politike na ostvarivanje koncepta održivog ruralnog razvoja.

Republika Srbija je usvojila strateške razvojne dokumente i sistem mera agrarne politike, koji je u funkciji održivog ruralnog razvoja. Organska poljoprivreda u potpunosti podržava postavljene strateške ciljeve i nedvosmisleno doprinosi ostvarivanju koncepta održivog ruralnog razvoja. Na razvoj organske poljopivrede veliki uticaj imaju, pored institucionalno-pravnog okvira, subvencije iz agrarnog budžeta. One stimulativno deluju na povećanje površina pod organskom poljoprivredom i na ekonomsku motivaciju proizvođača. Visina subvencija determinisana je brojnim faktorima, a samo u manjoj meri stvarnim potrebama agrara i ruralnih područja. Nekonzistentan sistem subvencinisanja jedan je od razloga sporijeg rasta površina pod organskom proizvodnjom.

Ipak, organska proizvodnja u poslednjoj deceniji beleži blagi trend rasta, što se može pripisati stimulativnim merama agrarne politike, odnosno značajnom povećanju subvencija. Ukoliko se nastavi s praksom povećanja subvencija realno je za očekivati da se dinamičniji razvoj organske proizvodnje nastavi i u predstojećem periodu i time doprinese boljem ostvarivanju koncepta održivog ruralnog razvoja.
\end{abstract}

Ključne reči: agrarna politika, agrarni budžet, organska poljoprivreda, održivi razvoj, Republika Srbija.

\begin{abstract}
The aim of this paper is to determine the contribution of agricultural policy measures to the realization of the concept of sustainable rural development of the Republic of Serbia. Considering that organic production mostly contributes to the ecological sustainability of rural areas, the paper analyzes the impact of subsidies on the expansion of this production in our country. Thus, indirectly, the impact of agricultural policy measures on the realization of the concept of sustainable rural development is analyzed.

The Republic of Serbia has adopted strategic development documents and a system of agricultural policy measures, which is in the function of sustainable rural development. Organic agriculture fully supports the set strategic goals and unequivocally contributes to the realization of the concept of sustainable rural development. In addition to the institutional and legal framework, subsidies from the agricultural budget have a great influence on the development of organic farming. They have a stimulating effect on increasing the area under organic agriculture and on the economic motivation of producers. The amount of subsidies is determined by a number of factors, and only to a lesser extent by the real needs of farmers and rural areas. An inconsistent subsidy system is one of the reasons for the slower growth of areas under organic production.
\end{abstract}


However, organic production has recorded a slight growth trend in the last decade, which can be attributed to stimulative measures of agricultural policy, ie a significant increase in subsidies. If the practice of increasing subsidies continues, it is realistic to expect that the more dynamic development of organic production will continue in the coming period and thus contribute to a better realization of the concept of sustainable rural development.

Keywords: agrarian policy, agrarian budget, organic agriculture, sustainable development, Republic of Serbia.

\footnotetext{
${ }^{1}$ orcid.org/0000-0003-4587-4855, e-mail: katarina.djuric@polj.uns.ac.rs

${ }^{2} e$-mail: ivanisevicdragan67@gmail.com

${ }^{3}$ e-mail: miralem.jahic.59@gmail.com

${ }^{4}$ orcid.org/0000-0002-7088-8506, e-mail: rprodanovic@fimek.edu.rs
}

\section{UVOD / INTRODUCTION}

Kraj XX veka karakterišu značajne promene, koje su zahvatile veliki broj oblasti poput politike, ekonomije, tehnologije, medicine, finansija, ekologije i poljoprivrede. U svim oblastima zabeležen je veliki broj inovacija, koje obezbeđuju niz pozitivnih efekata. Međutim, ubrzan tehnološki razvoj donosi i određene negativne posledice, koje se manifestuju, pre svega, u obasti prirodnih resursa i životne sredine. U takvim okolnostima, koncept održivog razvoja dobija sve više na značaju zbog pitanja opstanka i daljeg ekonomskog napretka, kako na globalnom, tako i na regionalnom i nacionalnom nivou (Mc Neill, 2019).

Održivi razvoj je u sprezi je sa različitim sektorskim politikama, a između ostalog i sa agrarnom i ruralnom politikom. Mere agrarne politike prevashodno su definisane, kako bi obezbedile zadovoljavanje potreba potrošača za kvalitetnom hranom i drugim proizvodima, ali i ostvarivanjem sigurnog dohotka poljoprivrednika. Međutim, poslednjih decenija, agrarna politika, naročito u ekonomski razvijenom delu sveta, sve je više bazirana na tome da se primenom njenih mera očuva biodiverzitet, kvalitet prirodnih resursa i podstakne proizvodnja zdravstveno bezbedne hrane (Đurić et al., 2019).

Shodno globalnim razvojnim tendencijama i Republika Srbija definisala je svoje strateške ciljeve u oblasti agrara. Dokumentom „Strategija poljoprivrede i ruralnog razvoja Republike Srbije“ (2014-2024), naša zemlja je napravila značajan zaokret u pravcu poštovanja principa održivog ruralnog razvoja i očuvanja životne sredine. S obzirom da je organska poljoprivreda prepoznata, kao sistem proizvodnje u kome se u potpunosti poštuju principi održivog razvoja, deo Strategije usmeren je na stvaranje povoljnih uslova za razvoj ovog sistema proizvodnje. Siguran način da se organska poljoprivreda u većoj meri afirmiše je njeno adekvatno finasiranje, kroz sistem subvencija i budžetskih podsticaja.

\section{METODI ISTRAŽIVANJA / RESEARCH METHODS}

Cilj rada je utvrđivanje doprinosa mera agrarne politike ostvarivanju održivog ruralnog razvoja $\mathrm{Re}$ publike Srbije. Akcenat u istraživanju usmeren je na mere podrške, pre svega, organskoj poljoprivredi, kao faktoru koji ima izuzetno pozitivan uticaj na ostvarivanje ekološke održivosti u okviru agrarnog i ruralnog razvoja.

S obzirom da organska poljoprivreda predstavlja sistem proizvodnje hrane, koji ima izraženu ekološku komponentu, kao i to da je u zemljama Evropske unije jedan od modela ruralnog razvoja (Đurić et al., 2019), čini se opravdanim istraživanje mogućnosti njenog razvoja u Republici Srbiji, kroz analizu sistema budžetske podrške.

$\cup$ radu su primenjeni descriptivni metodi, a takođe metodi analize i sinteze u delu o poljoprivredi i organskoj poljoprivredi.

\section{REZULTATI I DISKUSIJA / RESULTS AND DISCUSSION}

\subsection{Mesto održivog razvoja u strateškim razvojnim} dokumentima Republike Srbije /

The place of sustainable development in the strategic development documents of the Republic of Serbia

Polazna osnova pri izradi Strategije održivog razvoja Republike Srbije (SOR, 2007) bila je da se uz uvažavanje postojećih usvojenih strateških dokumenata izradi koncept održivog razvoja, koji sinergijski povezuje sve tri komponente - ekonomiju, društvo i životnu sredinu. Da bi se to postiglo, prvo je izvršena analiza postojećih sektorskih i međusektorskih strategija. Prema ovom dokumentu, održivi razvoj definiše se kao ciljno orijentisan, dugoročan, neprekidan, sveobuhvatan i sinergetski proces, koji utiče na sve aspekte života (ekonomski, socijalni, ekološki i institucionalni) na svim nivoima (SOR, 2007). Posebna pažnja u Strategiji održivog razvoja posvećena je poljoprivredi i njenom uticaju 
na životnu sredinu i očuvanje biodiverziteta. Ciljevi održivog razvoja poljoprivrede obuhvataju (SOR, 2007):

- Usklađivanje nacionalnih propisa i akcija iz oblasti poljoprivrede sa zakonodavstvom i praksom u Evropskoj uniji;

- Podsticanje investicija u smanjenje zagađenja iz poljoprivrede, očuvanje agrobiodiverziteta i tradicionalnih sistema farmi, radi očuvanja predeonog i specijskog biodiverziteta u osetljivim agroekološkim uslovima, razvoj sistema zaštite dobrobiti životinja, smanjenje erozije, te očuvanje i unapređenje životne sredine u celini;

- Povećanje površina pod organskom i drugim ekološki prihvatljivim sistemima proizvodnje;

- Podizanje i razvijanje javne svesti poljoprivrednih proizvođača o problemima životne sredine, uz uvažavanje principa zaštite biodiverziteta i dobrobiti životinja;

- Uvođenje kodeksa dobre poljoprivredne prakse.

Jedan od predloga koji je dat u ovom razvojnom dokumentu je osnivanje nacionalne laboratorije za bezbednost hrane, koja bi uticala na podizanje kvalitata poljoprivednih i prehrambenih proizvoda, ali i na očuvanje životne sredine, kroz uvođenje adekvatnih tehnologija u poljoprivredu i prehrambenu industriju. Stvaranje povoljnih društvenih efekata kroz primenu multifunkcionalnog razvoja ruralnih područja trebalo bi da ostvari mnogostruke pozitivne efekte u političkom, demografskom, kulturnom, pa čak i bezbedonosnom smislu. Osnovni cilj poljoprivrede i njen doprinos održivom razvoju ogleda se u organizovanju ekonomski isplative i ekološki prihvatljive proizvodnje, koja bi bila okosnica ruralnog razvoja u oblastima u kojima postoje povoljni prirodni uslovi, odnosno da se postigne odgovarajući nivo konkurentnosti, pre svega, na domaćem, a potom i na inostranom tržištu.

Okvirni strateški dokument za oblast poljoprivrede i ruralnog razvoja u Republici Srbiji usvojen je 2014. godine, a odnosi se na period do 2024. godine. Strategijom poljoprivrede i ruralnog razvoja utvrđeni su sledeći ciljevi (MPŠV, 2014):

- Rast proizvodnje i stabilnost dohotka poljoprivrednika,

- Rast konkurentnosti uz prilagođavanje zahtevima domaćeg i inostranog tržišta i tehničko-tehnološko unapređenje sektora poljoprivrede,

- Održivo upravljanje resursima i zaštita životne sredine,
- Unapređenje kvaliteta života u ruralnim područjima i smanjenje siromaštva,

- Efikasno upravljanje javnim politikama i unapređenje institucionalnog okvira za razvoj poljoprivrede i ruralnih područja.

Realizacija vizije poljoprivrede, kao sektora koji obezbeđuje prehrambenu sigurnost stanovništva, dostatan dohodak proizvođačima i očuvanje biodiverziteta, trebalo bi da se zasniva na sledećih nekoliko principa: (1) tehničko-tehnološki napredak i inovacije; (2) odgovorno upravljanje prirodnim resursima i (3) zaustavljanje dalje depopulacije sela.

Jedan od sistema poljoprivredne proizvodnje, koji u potpunosti podržava postavljene strateške ciljeve i nedvosmisleno doprinosi ostvarivanju održivog razvoja je organska poljoprivreda. Naime, organska poljoprivreda sa svojim principima može podržati održivi razvoj, jer nastoji da očuva prirodne resurse za buduće generacije (Janković, Jovanović, 2018). Od uvođenja Zakona o organskoj proizvodnji i organskim proizvodima 2006. godine, u Republici Srbiji se konstantno povećavaju površine pod ovom proizvodnjom. Prema zvaničnim statističkim podacima, ogranska biljna proizvodnja je najzastupljenija na području AP Vojvodine ( $72 \%$ površina), zatim u regionima Južne i Istočne Srbije (16\%), Šumadije i Zapadne Srbije (11\%) (Kvrgić, Ristić, 2018). Najzastupljeniji usevi u ovom sistemu proizvodnje su: kukuruz, pšenica, soja, šljiva, jabuka i malina, dok se u okviru organske stočarske proizvodnje najviše gaje: ovce, živina i goveda.

Domaće tržište organskih poljoprivrednih i prehrambenih proizvoda nije još uvek dovoljno razvijeno. Njegov dinamičniji razvoj ograničen je nedovoljnom edukacijom, kako proizvođača, tako i potrošača, kao i neadekvatnom promocijom organskih proizvoda. Ipak, kao ključni faktor koji limitira razvoj domaćeg tržišta organske hrane izdvaja se niska kupovna moć najvećeg dela potrošača. Shodno tome, najveći deo organskih poljoprivrednih proizvoda namenjen je izvozu. U strukturi izvoza najzastupljenije je zamrznuto voće, koje čini $72 \%$ od ukupne količine organskih proizvoda. Izvoz se najvećim delom realizuje u Austriji, Nemačkoj, Holandiji i Italiji.

U cilju promocije i veće zastupljenosti organske poljoprivredne proizvodnje u Republici Srbiji je usvojen novi Zakon o organskoj proizvodnji (2010), kao i Pravilnik o kontroli i sertifikaciji u organskoj proizvodnji i metodama organske proizvodnje (2011). Pored institucionalnog, odnosno zakonodavnopravnog okvira, podršku razvoju organske proizvodnje i ostvarivanju održivog razvoja poljoprivrede i ruralnih područja Republika Srbija ostvaruje putem subvencija namenjenih za ovaj vid proizvodnje. $\mathrm{Na}$ 
taj način, stimulativno se deluje, ne samo na povećanje površina pod organskom poljoprivredom, već i na ekonomsku motivaciju, pre svega mladog stanovništva za ostanak na selu i bavljenje poljoprivredom.

\subsection{Budžetska podrška poljoprivredi u Republici Srbiji / \\ Budget support for agriculture in the Republic of Serbia}

Najvažniji izvor sredstava državne podrške poljoprivredi i ruralnom razvoju je agrarni budžet. Agrarni budžet je deo ukupnog budžeta Republike Srbije, koji je uveden u političku praksu naše zemlje 1996. godine, sa ciljem da obezbedi stabilne finansijske izvore za podsticanje razvoja poljoprivrede i ruralnih područja. Za svaku budžetsku godinu, Vlada propisuje obim sredstava, vrste i maksimalne iznose po pojedinim vrstama podsticaja.

U skladu sa zakonskom regulativom Republike Srbije iz oblasti podsticaja u poljoprivredi i ruralnom razvoju, razlikuju se sledeće vrste podsticaja (MPŠV, 2020):

- Direktna plaćanja,

- Kreditna podrška,

- Posebni podsticaji,

- Podsticaji za programe ruralnog razvoja.

Direktna plaćanja namenjena su subvencionisanju poljoprivredne proizvodnje i to u obliku premija za mleko, osnovnih podsticaja za biljnu proizvodnju, podsticaja za kvalitetna grla priplodne stoke, podsticaja za tov, podsticaja za košnice pčela i uzgoj ribe, kao i regresa za nabavku inputa i troškova skladištenja. Budući da se u poljoprivredi, usled visokog stepena zavisnosti proizvodnih rezultata od agroekoloških uslova, javlja sporiji obrt kapitala nego u drugim privrednim delatnostima, država obezbeđuje finansijsku podršku proizvođačima u vidu subvencionisanja dela kamatne stope. Podsticaji za sprovođenje odgajivačkih programa u stočarstvu, promotivne aktivnosti u poljoprivredi i ruralnom razvoju, kao i proizvodnju sadnog materijala, sertifikaciju i selekciju, realizuju se iz budžetskih sredstava u okviru grupe tzv. posebnih podsticaja. U cilju revitalizacije i napretka ruralnih područja u agrarnom budžetu su predviđena sredstva, koja se isplaćuju za programe ruralnog razvoja. Ovoj grupi subvencija pripradaju podsticaji za unapređenje konkurentnosti, podsticaji za unapređenje i očuvanje životne sredine i prirodnih resursa, podsticaji za diverzifikaciju dohotka i unapređenje kvaliteta života u ruralnim područjima, podsticaji za pripremu i sprovođenje lokalnih strategija ruralnog razvoja, kao i podsticaji za unapređenje sistema kreiranja i prenosa znanja.
Visina ukupnih budžetskih sredstava plasiranih u poljoprivredu i ruralni razvoj je opredeljena brojnim faktorima. Obim podrške je češće bio zavistan od ekonomskih prilika u zemlji i neophodnosti da se podmire potrebe drugih budžetskih korisnika, nego što je bio odraz realnih potreba agrara i ruralnih područja za finansijskom podrškom. I pored opšte tendencije rasta agrarnog bužeta, njegov udeo u ukupnom budžetu Republike Srbije od 2007. godine ne prelazi 5\% ukupnog nacionalnog budžeta (Kuzman et al., 2017).

Struktura agrarnog budžeta u Republici Srbiji po stubovima podrške tokom poslednjih decenija znatno je varirala. Osnovni uzroci takvih tendencija bili su nedostatak sredstava u budžetu u pojedinim godinama, usled čega su se pojedine mere gasile, kao i česte promene upravljačkih struktura, koje su po pravilu bile praćene radikalnim izmenama $u$ programima i sistemima podrške (Bajramović et al., 2016). Ipak, uočava se jedna zakonitost, a to je dominacija mera podrške tržištu i direktnih plaćanja proizvođačima u budžetskoj strukturi. Naime, u periodu od 2005. do 2014. godine, analiza agrarnog budžeta pokazuje da je učešće mera tržišne podrške i direktnih subvencija oko $77 \%$ u ukupnim subvencijama (Bajramović et al., 2016).

\subsection{Sistem subvencija namenjen organskoj poljoprivrednoj proizvodnji / \\ Subsidy system intended for organic agricultural production}

lako je razvoj poljoprivrede i ruralnih područja uslovljen delovanjem većeg broja faktora, kao jedan od najvažnijih, koji utiče na dinamiku razvoja agrarnog sektora, je finansijska podrška realizovana u vidu subvencija poljoprivrednim proizvođačima. S obzirom na to da je organska proizvodnja sistem proizvodnje koji u najvećoj meri doprinosi ekološkoj održivosti ruralnih područja, u radu je analiziran uticaj subvencija na ekspanziju ove proizvodnje u našoj zemlji. Time je, na posredan način, analiziran uticaj mera agrarne politike na ostvarivanje koncepta održivog ruralnog razvoja.

U okviru mera za podršku ruralnom razvoju za 2020. godinu izdvojeno je ukupno 6.077.200.000 dinara, što predstavlja $24,4 \%$ ukupnih sredstava agrarnog budžeta. U okviru ove grupe mera nalaze se podsticaji za očuvanje i unapređenje životne sredine i prirodnih resursa u iznosu od 504.000.000, što iznosi $8,3 \%$ od ukupnih sredstava namenjenih ruralnom razvoju. Od tog iznosa, planirano je da se u subvencije za organsku proizvodnju plasira 350.000 .000 dinara i to 150.000 .000 dinara u biljnu i 200.000.000 dinara u stočarsku proizvodnju (MPŠV, 2020). 
Prema Pravilniku o korišćenju podsticaja za organsku biljnu proizvodnju, resorno ministarstvo propisuje uslove, način i obrazac zahteva za ostva- rivanje prava na podsticaje, kao i maksimalan iznos podsticaja po korisniku (Tabela 1).

Tabela 1 - Subvencije za organsku biljnu poljoprivrednu proizvodnju u Republici Srbiji

Table 1 - Subsidies for organic plant agricultural production in the Republic of Serbia

\begin{tabular}{|c|c|c|}
\hline Godina & $\begin{array}{c}\text { Maksimalan iznos subvencija } \\
\text { po korisniku (din) }\end{array}$ & $\begin{array}{c}\text { Uvećanje subvencija za organsku proizvodnju u } \\
\text { odnosu na subvencije u konvencionalnoj proizvodnji }\end{array}$ \\
\hline 2018. & 136.000 & $70 \%$ \\
\hline 2019. & 228.800 & $120 \%$ \\
\hline 2020. & 520.000 & $400 \%$ \\
\hline
\end{tabular}

Izvor / Source: (Bajramović et al., 2016; MPŠV, 2018, 2019)

U prethodne tri godine uočava se dinamično povećanje budžetskih sredstava za podršku organskoj proizvodnji. Naime, u 2018. godini podsticaji za organsku biljnu proizvodnju utvrđeni su u iznosu, koji se uvećava za $70 \%$ u odnosu na iznos subvencija za konvencionalnu proizvodnju. U 2019. godini taj procenat povećan je na $120 \%$, a u 2020 . godini subvencije za organsku proizvodnju veće su za $400 \%$ u odnosu na konvencionalnu poljoprivredu (MPŠV, 2018, 2019, 2020a).

Prema Pravilniku o korišćenju podsticaja za organsku stočarsku proizvodnju, propisane su vrste podsticaja, uslovi, način ostvarivanja prava na podsticaje, obrasci zahteva za ostvarivanje prava na podsticaje, kao i maksimalan iznos podsticaja po korisniku i vrsti pojedine mere (MPŠV, 2013). Predviđeno je da se subvencije isplaćuju za premije za mleko proizvedeno metodom organske proizvodnje, tov junadi, jagnjadi, jaradi, svinja, krave doilje, koš- nice pčela, proizvodnju konzumne ribe, krave za uzgoj teladi za tov, kvalitetne priplodne mlečne krave, kvalitetne priplodne tovne krave i bikove, kvalitetne priplodne ovce i ovnove, koze i jarčeve, kvalitetne priplodne krmače i nerastove, roditeljske kokoške teškog tipa, roditeljske kokoške lakog tipa, roditeljske ćurke, kvalitetne priplodne matice riba šarana i kvalitetne priplodne matice riba pastrmke.

Kada je u pitanju subvencionisanje organske stočarske proizvodnje, za 2020. godinu predviđeno je da se subvencije povećavaju za $40 \%$ u odnosu na iznos subvencija u konvencionalnom stočarstvu. Osim toga, iz agrarnog budžeta obezbeđena su i sredstva za nabavku priključne mehanizacije, kao i sredstva za sufinansiranje troškova kontrole i sertifikacije organske proizvodnje i nabavku priključne mehanizacije za organsku proizvodnju (Tabela 2).

Tabela 2 - Ostale vrste subvencija u organsku poljoprivrednu proizvodnju u Republici Srbiji u 2020. godini

Table 2 - Other types of subsidies in organic agricultural production in the Republic of Serbia in 2020

\begin{tabular}{|l|c|c|}
\hline \multicolumn{1}{|c|}{ Vrsta subvencija } & $\begin{array}{c}\text { Maksimalan iznos } \\
\text { subvencija po korisniku (din) }\end{array}$ & $\begin{array}{c}\text { Ukupna sredstva } \\
\text { u 2020. godini }\end{array}$ \\
\hline Subvencije za organsku stočarsku proizvodnju & 55.000 .000 & 200.000 .000 \\
\hline $\begin{array}{l}\text { Sredstva za nabavku priključne mehanizacije za } \\
\text { organsku proizvodnju }\end{array}$ & 800.000 & 9.000 .000 \\
\hline $\begin{array}{l}\text { Sredstva za sufinansiranje troškova kontrole i } \\
\text { sertifikacije organske proizvodnje i nabavku } \\
\text { priključne mehanizacije za organsku proizvodnju }\end{array}$ & 1.000 .000 & 10.000 .000 \\
\hline
\end{tabular}

Izvor / Source: (MPŠV, 2020a)

Posmatrajući sve relevantne pokazatelje i statističke podatke za Republiku Srbiju, uočava se da organska proizvodnja u periodu od 2012. do 2018. godine beleži trend rasta (Tabela 3 ). Kontinuiran rast broja proizvođača, kao i površina na kojima se organizuje organska proizvodnja rezultat su, između ostalog, stimulativnih mera agrarne politike. S obzirom na intenziviranje postojećih i uvođenje novih subvencija za organsku proizvodnju u prethodne tri godine (Tabela 1 i Tabela 2) može se očekivati da se trend povećanja površina pod organskom proizvodnjom nastavi. Variranja koja se javljaju u pojedinim godinama, kada je u pitanju uzgoj svinja, ovaca i koza u organskom sistemu, mogu se dovesti u vezu sa nekonzistentnošću pojedinih mera podrške za navedene linije proizvodnje. 
Tabela 3 - Organska proizvodnja u Republici Srbiji u periodu od 2012. do 2018. godine

Table 3 - Organic production in the Republic of Serbia in the period from 2012 to 2018

\begin{tabular}{|l|c|c|c|c|c|c|c|c|c|}
\hline \multirow{2}{*}{ Godina } & \multirow{2}{*}{$\begin{array}{c}\text { Broj } \\
\text { proizvođača }\end{array}$} & $\begin{array}{c}\text { Na kojoj se } \\
\text { obavlja } \\
\text { proizvodnja }\end{array}$ & $\begin{array}{c}\text { Površina (ha) } \\
\text { konverziji }\end{array}$ & Ukupno & Goveda & Svinje & Ovce & Koze & Živina \\
\hline 2012. & 1061 & 2085 & 4255 & 6340 & 1219 & 47 & 271 & 0 & 241 \\
\hline 2013. & 1280 & 3187 & 5041 & 8228 & 1853 & 57 & 2793 & 81 & 1362 \\
\hline 2014. & 1866 & 4671 & 4877 & 9548 & 2557 & 44 & 1285 & 182 & 1035 \\
\hline 2015. & 2289 & 7628 & 7670 & 15298 & 2746 & 232 & 4846 & 1686 & 1380 \\
\hline 2016. & 3184 & 7391 & 6967 & 14385 & 2895 & 283 & 4378 & 1406 & 3158 \\
\hline 2017. & 6154 & 7504 & 5919 & 13423 & 3094 & 87 & 4665 & 248 & 4415 \\
\hline 2018. & 6709 & 12655 & 6600 & 19255 & 3594 & 284 & 5138 & 1486 & 6735 \\
\hline
\end{tabular}

Izvor / Source: (RZS, 2016, 2017, 2018)

\section{ZAKLJUČAK / CONCLUSION}

U svim strateškim dokumentima novijeg datuma Republika Srbija napravila je značajan zaokret prema konceptu održivog razvoja. U skladu sa definisanim dugoročnim ciljevima u oblasti poljoprivrede, usmeravaju se i sredstva za finansiranje iz nacionalnog budžeta. lako znatno ispod realnih potreba primarnog sektora, agrarni budžet Republike Srbije deo sredstava usmerava za podsticaje organske poljoprivredne proizvodnje.

Iz godine u godinu iznos i obuhvat subvencija se povećavaju, pa je realno očekivati da se rast organske poljoprivredne proizvodnje nastavi i u predstojećem periodu. Međutim, ono što se, sa aspekta poljoprivrednih proizvođača, javlja kao značajno ograničenje rastu ove proizvodnje je hronični nedostatak radne snage, odnosno radno aktivnog stanovništva u ruralnim područjima. Kako bi se ovaj problem ublažio, a vremenom i prevazišao, neophodno je dodatno intenziviranje mera podrške mladim poljoprivrednicima. Kombinacijom te dve vrste podsticaja, omogućio bi se dinamičan rast organske poljoprivrede i diverzifikacija ruralne ekonomije, što predstavlja dobru osnovu za ostvarivanje održivog razvoja ruralnih područja, kako sa ekološkog, tako i sa ekonomskog i socijalnog aspekta.

\section{Zahvalnica / Acknowledgement}

Sredstva za realizaciju istraživanja obezbeđena su od strane Ministarstva za prosvetu, nauku i tehnološki razvoj Republike Srbije (ugovor 451-03-9/202114/200117).

\section{LITERATURA / REFERENCES}

[1] Bajramović, N., Bogdanov, N., Butković, J., Dimitrievski, D., Erjavec, E., Gjeci, G., Gjokaj, E., Hoxha, B., Stomenkovska, I.J., Konjević, D., Kotevska, A., Martinović, A., Miftari, I., Nacka, M., Ognjenović, D., Rednak, M., Tuna, E., Volk, T.,
Zhllima, E. (2016), In: Volk, T., Erjavec, E., Ciaian, P. and Gomez, S. y Paloma (editors): Analysis of the agricultural and rural development policies of the Western Balkan countries. EUR 27898 EN, Joint Research Centre, European Commission, doi:10.2791/744295

[2] Đurić, K., Cvijanović, D., Prodanović, R., Čavlin, M., Kuzman, B., Lukač Bulatović, M. (2019), Serbian Agriculture Policy: Economic Analysis Using the PSE Approach. Sustainability, 11(2), 309.

[3] Foti, V.T., Scuderi, A., Timpanaro, G. (2013), Organic social agriculture: A tool for rural development. Quality - Access to Success, 14(1), 266271.

[4] Janković, M., Jovanović, L. (2018), Organska poljoprivreda i zelena ekonomija. Ecologica, 25 (91), 507-511.

[5] Kuzman, B., Đurić, K., Mitrović, Lj., Prodanović, R. (2017), Agricultural Budget and Agricultural Development in Republic of Serbia. Economics of Agriculture, 64, (2), 515-531.

[6] Kvrgić, G., Ristić, L. (2018), Unutrašnji izazovi održivog razvoja ruralnih područja Republike Srbije. Naučne publikacije Državnog univerziteta u Novom Pazaru. Serija B, Društvene i humanističke nauke, 1(1), 28-46.

[7] Mc Neill, D. (2019), The Contested Discourse of Sustainable Agriculture. Global Policy, Vol. 10, Issue S1 (Special Issue: Knowledge and Politics in Setting and Measuring SDGs), 16-27.

[8] MPŠV, (2013), Ministarstvo poljoprivrede šumarstva i vodoprivrede Republike Srbije: Pravilnik o korišćenju podsticaja za organsku stočarsku proizvodnju, Službeni glasnik Republike Srbije, broj 10/13, 142/14, 103/15, 101/16.

[9] MPŠV, (2014), Ministarstvo poljoprivrede šumarstva i vodoprivrede Republike Srbije: Strategija 
poljoprivrede i ruralnog razvoja Republike Srbije za period 2014 - 2024. godine. Službeni glasnik Republike Srbije, broj 85/2014.

[10] MPŠV, (2018), Ministarstvo poljoprivrede šumarstva i vodoprivrede Republike Srbije: Pravilnik o korišćenju podsticaja za organsku biljnu proizvodnju, Službeni glasnik Republike Srbije, broj $31 / 18$.

[11] MPŠV, (2019), Ministarstvo poljoprivrede šumarstva i vodoprivrede Republike Srbije: Pravilnik o izmenama pravilnika o korišćenju podsticaja za organsku biljnu proizvodnju, Službeni glasnik Republike Srbije, broj 23/2019.

[12] MPŠV, (2020), Ministarstvo poljoprivrede šumarstva i vodoprivrede Republike Srbije: Uredba o raspodeli podsticaja u poljoprivredi i ruralnom razvoju u 2020. godini, Službeni glasnik Republike Srbije, broj 1/20.
[13] MPŠV, (2020a), Ministarstvo poljoprivrede šumarstva i vodoprivrede Republike Srbije: Pravilnik o izmenama pravilnika o korišćenju podsticaja za organsku biljnu proizvodnju, Službeni glasnik Republike Srbije, broj 20/20.

[14] RZS, (2016), Republički zavod za statistiku: Statistički godišnjak Republike Srbije za 2016. god., Beograd.

[15] RZS, (2017), Republički zavod za statistiku: Statistički godišnjak Republike Srbije za 2017. god., Beograd.

[16] RZS, (2018), Republički zavod za statistiku: Statistički godišnjak Republike Srbije za 2018. god., Beograd.

[17] SOR, (2007), Vlada Republike Srbije: Nacionalna strategija održivog razvoja. Službeni glasnik Republike Srbije, broj 55/2005, 71/2005 i 101/07. 